\title{
Cognitive Effects of White Matter Pathology in Normal and Pathological Aging
}

\author{
Alar Kaskikallio ${ }^{\mathrm{a}, *}$, Mira Karrasch ${ }^{\mathrm{a}}$, Juha O. Rinne ${ }^{\mathrm{b}, \mathrm{c}}$, Terhi Tuokkola ${ }^{\mathrm{b}}$, Riitta Parkkola ${ }^{\mathrm{d}}$ \\ and Petra Grönholm-Nyman ${ }^{\mathrm{a}}$ \\ ${ }^{a}$ Department of Psychology, Åbo Akademi University, Finland \\ ${ }^{\mathrm{b}}$ Turku PET-Centre, University of Turku, Finland \\ ${ }^{\mathrm{c}}$ Division of Clinical Neurosciences, Turku University Hospital, Finland \\ ${ }^{\mathrm{d}}$ Department of Radiology, University and University Hospital of Turku, Finland
}

Accepted 14 November 2018

\begin{abstract}
We examined whether cerebrovascular white matter pathology is related to cognition as measured by the compound score of CERAD neuropsychological battery in cognitively normal older adults, patients with mild cognitive impairment, and patients with Alzheimer's disease (total $n=149$ ), controlling for age and education. Trend-level effects of white matter pathology on cognition were only observed in patients with Alzheimer's disease $\left(p=0.062, \eta^{2}=0.052\right)$, patients with severe frontal white matter pathology performed notably worse than those with milder pathology. This indicates that frontal cerebrovascular pathology may have an additive negative effect on cognition in Alzheimer's disease.
\end{abstract}

Keywords: Alzheimer's disease, cognition, mild cognitive impairment, white matter

\section{INTRODUCTION}

Aging is often associated with vascular white matter (WM) brain pathology [1]. The functional consequences of these brain changes are related to their severity and extent, and can range from almost none via mild cognitive decline to dementia. Furthermore, comorbid vascular brain changes are often present in patients with Alzheimer's disease (AD) [2], with a number of WM pathways having been implicated as manifesting significant degeneration in AD [3]. Additionally, cerebrovascular risk factors such as hypertension, smoking, and diabetes are also risk factors for $\mathrm{AD}$ [4].

\footnotetext{
*Correspondence to: Alar Kaskikallio, MA, Department of Psychology, Åbo Akademi University, Tehtaankatu 2, 20500 Turku, Finland. Tel.: +358 44 0610882; E-mail: alar.kaskikallio@ abo.fi.
}

Some studies have examined the effects of vascular brain changes on cognitive function in mild cognitive impairment (MCI) and AD. For example increased WM lesion load has been found to correlate with cognitive impairment in patients with $\mathrm{AD}$ [5], and shown to predict the rate of cognitive decline in $\mathrm{AD}$ [6]. Furthermore, Rizvi et al. [7] have described WM lesions as affecting cognition both directly and indirectly through grey matter thickness, similarly for both cognitively healthy and cognitively impaired (MCI/AD). However, comparing the differences of the effects on cognitive functions between the groups has not typically been the main focus. Increasing our knowledge of the effects that vascular changes can have on cognition would be especially relevant for clinicians working in cognitive assessment with MCI and $\mathrm{AD}$ patients. Thus, our purpose in the current study was to examine if WM changes are related to cognitive function in older adults, patients with MCI 
Table 1

Demographic and Clinical Characteristics of Study Participants

\begin{tabular}{|c|c|c|c|c|}
\hline & All & $\mathrm{C}$ & MCI & $\mathrm{AD}$ \\
\hline$n$ & 149 & 57 & 40 & 52 \\
\hline Women \% & $48 \%$ & $46 \%$ & $45 \%$ & $52 \%$ \\
\hline Age M (SD), y & $72.86(5.22)$ & $71.47(5.44)$ & $74.01(5.40)$ & $73.48(4.55)$ \\
\hline \multicolumn{5}{|l|}{ Education level: } \\
\hline Primary school & 73 & 22 & 19 & 32 \\
\hline Vocational school & 57 & 26 & 13 & 19 \\
\hline Upper secondary & 2 & 2 & 0 & 0 \\
\hline Academic degree & 16 & 7 & 8 & 1 \\
\hline CERAD Total Score, M (SD) & $79.23(15.27)$ & $87.75(10.48)$ & $80.82(11.68)$ & $68.92(16.28)$ \\
\hline \multicolumn{5}{|l|}{ WM Pathology: Frontal ${ }^{\mathrm{a}}$} \\
\hline none/focal & 98 & 41 & 25 & 32 \\
\hline b. confluent & 39 & 15 & 10 & 14 \\
\hline diffuse & 11 & 1 & 5 & 5 \\
\hline \multicolumn{5}{|l|}{ WM Pathology: Parieto-occipital ${ }^{\mathrm{a}}$} \\
\hline none/focal & 100 & 46 & 24 & 30 \\
\hline b. confluent & 37 & 8 & 12 & 17 \\
\hline diffuse & 11 & 3 & 3 & 5 \\
\hline
\end{tabular}

${ }^{a}$ Frontal MRI data is missing for one participant, and parieto-occipital data for another. b. confluent, beginning confluent; WM, white matter.

and patients with $\mathrm{AD}$, and whether there would be differences in the effects between the groups.

\section{METHODS}

The data used in this study has been collected as part of the DEMPET and TWINPIB research projects conducted at the National PET-Centre in Turku, Finland over many years. Both studies were performed in accordance with relevant guidelines and regulations and were approved by the Joint Ethical Committee of the University of Turku and Turku University City Hospital. The diagnosis of MCI was performed according to the Petersen et al. criteria [8], whereas patients with AD satisfied the DSM-IV criteria for dementia as well as the NINCDS-ADRDA (National Institute of Neurological and Communicative Disorders and Stroke/Alzheimer's Disease and Related Disorders Association) criteria for probable AD [9]. All participants underwent an extensive neuropsychological assessment (for an example, see Kemppainen et al. [10]). The Finnish version of the CERAD test battery [11] was included in this assessment, but was not used for group classification. In the current study a minimum score of 25 in the MiniMental State Examination was required for inclusion in the healthy adult control group, with two 24-point exceptions being admitted in light of their adequate level of cognitive performance. The final sample consists of 57 healthy adults, 40 patients with MCI, and 52 patients with $\mathrm{AD}$ (see Table 1 for demographical and clinical characteristics of study participants). The participants received oral and written information about the study and gave informed consent before their inclusion.

A total score for the CERAD test battery (CERADTS), computed by summing up the scores from a number of subtests, was first described by Chandler et al. [12], and then expanded by Seo et al. [13]. Both composite scores have shown high test-retest and interrater reliability [13], as well as validity in detecting MCI $[13,14]$ and $\operatorname{AD}[13,15]$. The expanded total score by Seo et al. was chosen for the current study. Due to missing data for some of the participants, the Word List Recognition score had to be computed without subtracting false positive recognitions from correct positives. Furthermore, two missing data points were imputed by EM missing data analysis in SPSS.

The MRI scanning of the subjects was performed with 1.5T Philips Intera (Best, the Netherlands). WM changes were analyzed using T2 and FLAIR (fluid attenuated inversion recovery) images. Our focus was on the WM changes in the frontal and parietooccipital lobes, since visual ratings of these regions have the highest interrater reliability [16]. Two radiologists analyzed the sequences independently on a personal computer, using the Wahlund scale ranging from 0 (no lesions) to 3 (confluent lesions) [16]. The higher one of the two scores was assigned as the final hemispheric WM score. Measures were given for the frontal and parieto-occipital lobes in the left and right hemispheres separately, after which the hemispheric scores were combined to form summary 
scores. These were further transformed into a threelevel categorical variable ranging from none/focal changes (0-2 points in the hemispheric summary score), through beginning confluent changes (3-4 points) to diffuse changes (5-6 points). This was performed for both the frontal and parieto-occipital regions.

For statistical analyses, we first examined any potential age, education, and gender effects by conducting a series of parametric (independent samples $t$-test) and non-parametric (Mann-Whitney's U-test, Pearson's chi-square) tests. Possible differences in cognitive performance between the groups were analyzed by a series of independent samples $t$-tests. For testing our main research questions, we conducted separate univariate ANOVAs, for the frontal and parieto-occipital regions respectively, with age and level of education as covariates and the CERADTS score as the dependent variable. One participant had to be excluded from the frontal analysis due to missing MRI data and another was excluded from the parieto-occipital analysis for the same reason. Data analysis was performed using the IBM SPSS statistics software v. 24.

\section{RESULTS}

Demographic and clinical characteristics of study participants are presented in Table 1. There were some differences regarding the demographic char- acteristics, but of a very small magnitude: The control group was younger than the MCI group, $\mathrm{t}(95)$ $=-2.27, p<0.05, d=0.05$, and the $\mathrm{AD}$ group, $\mathrm{t}(107)$ $=-2.08, p<0.05, d=0.04$, and also more educated than the AD group, $U=1070.50, z=-2.78, p=0.005$, $\eta^{2}=0.06$. The distribution of gender was the same across the groups, $\chi^{2}(2)=0.59, p=0.745$.

As would be expected, the control group had higher cognitive performance than the MCI group, $\mathrm{t}(95)$ $=3.17, p=0.002, d=0.07$, and the $\mathrm{AD}$ group, $\mathrm{t}(107)$ $=7.32, p<0.001, d=0.14$, and the MCI group fared better than the AD group, $\mathrm{t}(90)=3.90, p<0.001$, $d=0.08$.

The results regarding the analysis of the main study variables can be found in Table 2. Concerning cerebrovascular pathology, no significant main effects of WM pathology on cognitive performance were encountered. However, a significant interaction effect between the group and level of frontal WM changes was found. The control group contained a single participant with diffuse WM changes, who also had unusually high cognitive test scores. In order to examine whether this single participant may have affected the results, we removed the participant and rerun the analysis. After this, the interaction term between group and level of frontal WM changes no longer reached the 0.05 alpha level, but was very close. Moreover, the effect size was still nearly moderate, which indicates that the interaction explained a considerable amount of variation. This trend level interaction was due to the fact that $\mathrm{AD}$ patients with

Table 2

Univariate ANOVA results of the study variables

\begin{tabular}{|c|c|c|c|c|c|c|}
\hline Analysis & IV & $\mathrm{df}$ & Mean Square & $\mathrm{F}$ & $p$ & $\eta^{2}$ \\
\hline \multicolumn{7}{|l|}{ Frontal } \\
\hline \multirow[t]{3}{*}{ Unadjusted } & Group & 2,139 & 3068.79 & 18.95 & 0.000 & 0.214 \\
\hline & WM Score & 2,139 & 14.78 & 0.09 & 0.913 & 0.001 \\
\hline & Group * WM Score & 4,139 & 394.70 & 2.44 & 0.050 & 0.066 \\
\hline \multirow[t]{3}{*}{ Adjusted $^{\mathrm{a}}$} & Group & 2,137 & 2569.26 & 17.82 & 0.000 & 0.206 \\
\hline & WM Score & 2,137 & 8.08 & 0.06 & 0.946 & 0.001 \\
\hline & Group * WM Score & 4,137 & 402.06 & 2.79 & 0.029 & 0.075 \\
\hline \multirow{3}{*}{$\begin{array}{l}\text { Adjusted + } \\
\text { removed } \\
\text { outlier }^{b}\end{array}$} & Group & 2,137 & 2934.42 & 20.347 & 0.000 & 0.229 \\
\hline & WM Score & 2,137 & 372.90 & 2.586 & 0.079 & 0.036 \\
\hline & Group * WM Score & 3,137 & 360.39 & 2.499 & $0.062^{c}$ & 0.052 \\
\hline \multicolumn{7}{|c|}{ Parieto-Occipital } \\
\hline \multirow[t]{3}{*}{ Unadjusted } & Group & 2,139 & 2769.91 & 15.91 & 0.000 & 0.186 \\
\hline & WM Score & 2,139 & 18.58 & 0.11 & 0.899 & 0.002 \\
\hline & Group * WM Score & 4,139 & 98.70 & 0.57 & 0.687 & 0.016 \\
\hline \multirow[t]{3}{*}{ Adjusted $^{\mathrm{a}}$} & Group & 2,137 & 2245.56 & 14.54 & 0.000 & 0.175 \\
\hline & WM Score & 2,137 & 8.65 & 0.06 & 0.946 & 0.001 \\
\hline & Group * WM Score & 4,137 & 174.15 & 1.13 & 0.346 & 0.032 \\
\hline
\end{tabular}

${ }^{a}$ The results have been adjusted for education and age. ${ }^{\mathrm{b}}$ The results have been adjusted for education and age, and an outlier has been removed. ${ }^{\mathrm{c}}$ Trend-level significance. 
confluent WM lesions performed worse than those with less WM changes.

\section{DISCUSSION}

The focus of this study was to examine if WM pathology, specifically in frontal and occipito-parietal areas, is related to cognitive function in older adults, patients with MCI and patients with $\mathrm{AD}$, as measured with the CERAD-TS. These areas were chosen since visual ratings of them have shown the highest interrater reliability [16]. As expected, significant differences in cognitive function were found between all three groups; highest performances were found in the control group, intermediate performances in the MCI group and lowest test scores in the AD group. Additionally, a significant interaction effect was found between group and the level of frontal WM changes. After removing an outlier from the control group, the interaction term fell below statistical significance, but only marginally so $(p=0.062)$. The effect size remained nearly moderate, indicating that the interaction still explained a considerable amount of variation. AD patients with severe frontal WM changes had the lowest cognitive performances, notably lower than AD patients with milder levels of frontal WM pathology (see Fig. 1). Frontal and temporal WM lesions have been found to correlate with the CERAD-TS in mixed groups (C/MCI/AD) [5], but our study indicates that at least the changes relating to the frontal WM pathology may stem from patients with dementia of the AD type.

Parieto-occipital WM changes were not related to cognitive performance in any of the groups. One explanation for this might be the fact that most of the CERAD subtests place relatively more emphasis on verbal than visuospatial functions. Thus, multidomain cognitive analyses would be recommended in the future.

In addition to a cross-sectional design, uneven group sizes are a limitation of the current study. The none/focal WM changes group is overrepresented, whereas the diffuse WM changes group is substantially smaller in size, which can amplify the possibility of a type II error.

The effects of WM pathology on cognition in cognitively healthy adults, MCI, and AD have been examined in some studies, though comparing the differences of the effects between groups has not typically been the main focus. For example, previous studies have shown connections between WM

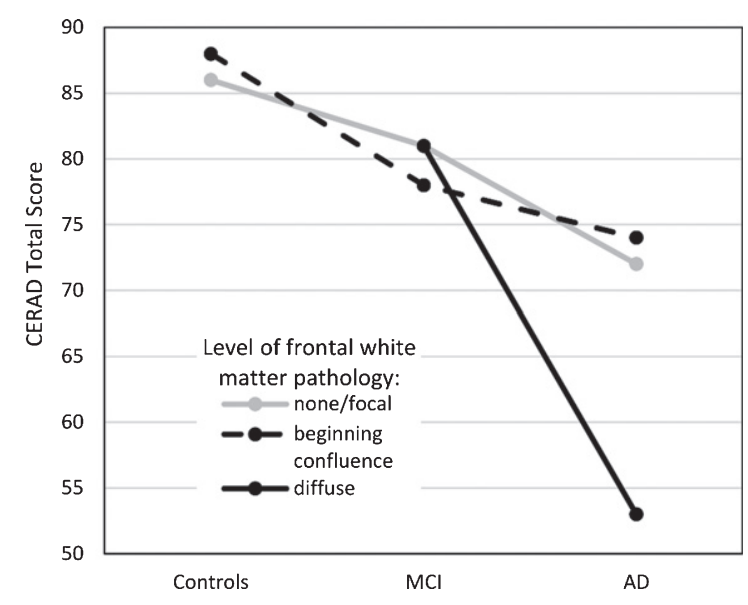

Fig. 1. Cognitive performance (as measured by the CERAD Total Score, range 0-115) in the three patient groups as a function of frontal white matter pathology. Estimated marginal means reported. MCI, mild cognitive impairment; AD, Alzheimer's disease.

changes and the rate of cognitive decline in $\mathrm{AD}$ [6], and the incidence of dementia in elderly individuals [17], as well as correlations between WM lesions in the corpus callosum and the fornices and global cognition in AD patients [5].

Furthermore, these phenomena have also been examined from another perspective, as some studies have studied the effects of amyloid pathology in patients with subcortical vascular dementia (for a review, see [18]). Park et al. [19] found that cognitive performance in immediate and delayed memory tasks was significantly worse in subcortical vascular dementia patients with extreme amyloidosis, suggesting that amyloid pathology has an independent effect on memory performance in the presence of cerebrovascular pathology. It is noteworthy, that while some studies have reported that cerebrovascular and AD pathology measures were uncorrelated [20], other studies have suggested the possibility for independent processes as well as interactions between these pathologies [21].

In summary, the current study builds on previous research concerning the interplay between $\mathrm{AD}$ and cerebrovascular pathology, and results indicate that concomitant frontal WM lesions in $\mathrm{AD}$ patients may lead to additive decline in cognitive functioning. To our knowledge we are the first ones to report this additivity of cognitive impairments in relation to specifically frontal WM lesions in AD. Furthermore, from a clinical perspective it is noteworthy that these can be detectable even when using rough general-level cognitive measures. 
Further studies are needed to elucidate whether domain-specific effects can be found using more sophisticated neuropsychological instruments. Using quantitative methods that allow for more localized analyses of vascular pathology could also shed light on the relationship between vascular pathology and its cognitive repercussions in $\mathrm{AD}$.

\section{ACKNOWLEDGMENTS}

Alar Kaskikallio was funded by the Department of Psychology at Åbo Akademi University. We also wish to thank the National PET-Centre in Turku for providing the research data.

Authors' disclosures available online (https:// www.j-alz.com/manuscript-disclosures/18-0554r2).

\section{REFERENCES}

[1] Feigin VL, Lawes CMM, Bennett DA, Anderson CS, West F (2003) Stroke epidemiology: A review of population- based studies of incidence, prevalence, and case-fatality in the late 20th century. Lancet Neurol 2, 43-53.

[2] Smith E (2016) Vascular cognitive impairment. Contin Lifelong Learn Neurol 22, 490-509.

[3] Mito R, Raffelt D, Dhollander T, VAughan DN, Tournier JD, Salvado O, Brodtmann A, Rowe CC, Villemagne VL, Connelly A (2018) Fibre-specific white matter reductions in Alzheimer's disease and mild cognitive impairment. Brain 141, 888-902.

[4] Duron E, Hanon O (2008) Vascular risk factors, cognitive decline, and dementia. Vasc Health Risk Manag 4, 363-381.

[5] Bilello M, Doshi J, Nabavizadeh SA, Toledo JB, Erus G, Xie SX, Trojanowski JQ, Han X, Davatzikos C (2015) Correlating cognitive decline with white matter lesion and brain atrophy MRI measurements in Alzheimer's disease. J Alzheimers Dis 48, 987-994.

[6] Brickman AM, Honig LS, Scarmeas N, Tatarina O, Sanders L, Albert MS, Brandt J, Blacker D, Stern Y (2008) Measuring cerebral atrophy and white matter hyperintensity burden to predict the rate of cognitive decline in Alzheimer disease. Arch Neurol 65, 1202-1208.

[7] Rizvi B, Narkhede A, Last BS, Budge M, Tosto G, Manly JJ, Schupf N, Mayeux R, Brickman AM (2017) The effect of white matter hyperintensities on cognition is mediated by cortical atrophy. Neurobiol Aging 64, 25-32.

[8] Petersen RC, Stevens JC, Ganguli M, Tangalos EG, Cummings JL, DeKosky ST (2001) Practice parameter: Early detection of dementia: Mild cognitive impairment (an evidence-based review). Neurology 56, 1133-1142.

[9] McKhann G, Drachman D, Folstein M, Katzman R, Price D, Stadlan EM (1984) Clinical diagnosis of Alzheimer's disease: Report of the NINCDS-ADRDA Work Group under the auspices of Department of Health and Human Services Task Force on Alzheimer's Disease. Neurology 34, 939-944.
[10] Kemppainen NM, Aalto S, Karrasch M, Någren K, Savisto N, Oikonen V, Viitanen M, Parkkola R, Rinne JO (2008) Cognitive reserve hypothesis: Pittsburgh compound $\mathrm{B}$ and fluorodeoxyglucose positron emission tomography in relation to education in mild Alzheimer's disease. Ann Neurol 63, 112-118.

[11] Morris JC, Heyman A, Mohs RC, Hughes JP, Vanbelle G, Fillenbaum G, Mellits ED, Clark C (1989) The consortium to establish a registry for Alzheimer's disease (CERAD). Clinical and neuropsychological assessment of Alzheimer's disease. Neurology 39, 1159-1165.

[12] Chandler MJ, Lacritz LH, Hynan LS, Barnard HD, Allen G, Deschner M, Weiner MF, Cullum CM (2005) A total score for the CERAD neuropsychological battery. Neurology $\mathbf{6 5}$, 102-106.

[13] Seo EH, Lee DY, Lee JH, Choo IH, Kim JW, Kim SG, Park SY, Shin JH, Do YJ, Yoon JC, Jhoo JH, Kim KW, Woo JI (2010) Total scores of the CERAD neuropsychological assessment battery: Validation for mild cognitive impairment and dementia patients with diverse etiologies. Am J Geriatr Psychiatry 18, 801-809.

[14] Paajanen T, Hänninen T, Tunnard C, Mecocci P, Sobow T, Tsolaki M, Vellas B, Lovestone S, Soininen H, AddNeuroMed Consortium (2010) CERAD neuropsychological battery total score in multinational mild cognitive impairment and control populations: The AddNeuroMed study. $J$ Alzheimers Dis 22, 1089-1097.

[15] Paajanen T, Hänninen T, Tunnard C, Hallikainen M, Mecocci P, Sobow T, Tsolaki M, Vellas B, Lovestone S, Soininen H (2014) CERAD neuropsychological compound scores are accurate in detecting prodromal Alzheimer's disease: A prospective AddNeuroMed study. J Alzheimers Dis 39, 679-690.

[16] Wahlund LO, Barkhof F, Fazekas F, Bronge L, Augustin M, Sjögren M, Wallin A, Ader H, Leys D, Pantoni L, Pasquier F, Erkinjuntti T, Scheltens P (2001) EuropeanTask Force on Age-Related White Matter Changes. A new rating scale for age-related white matter changes applicable to MRI and CT. Stroke 32, 1318-1322.

[17] Mortimer JA (2012) The Nun Study: Risk factors for pathology and clinical-pathologic correlations. Curr Alzheimer Res 9, 621-627.

[18] Kapasi A, DeCarli C, Schneider JA (2017) Impact of multiple pathologies on the threshold for clinically overt dementia. Acta Neuropathol 134, 171-186.

[19] Park J-H, Seo SW, Kim C, Kim SH, Kim GH, Kim ST, Jeon S, Lee JM, Oh SJ, Kim JS, Choe YS, Lee K-H, Shin JS, Kim CH, Noh Y, Cho H, Yoon CW, Kim HJ, Ye BS, Ewers M, Weiner MW, Lee J-H, Werring DJ, Na DL (2014) Effects of cerebrovascular disease and amyloid beta burden on cognition in subjects with subcortical vascular cognitive impairment. Neurobiol Aging 35, 254-260.

[20] Marchant NL, Reed BR, Sanossian N, Madison CM, Kriger S, Dhada R, Mack WJ, DeCarli C, Weiner MW, Mungas DM, Chui HC, Jagust WJ (2013) The aging brain and cognition: Contribution of vascular injury and $A \beta$ to mild cognitive dysfunction. JAMA Neurol 70, 488-495.

[21] Hughes TM, Kuller LH, Barinas-Mitchell EJM, Mackey RH, McDade EM, Klunk WE, Aizenstein HJ, Cohen AD, Snitz BE, Mathis CA, DeKosky ST, Lopez OL (2013) Pulse wave velocity is associated with $\beta$-amyloid deposition in the brains of very elderly adults. Neurology $81,1711-1718$. 